\title{
Clinical outcomes and toxicity of proton radiotherapy for vestibular schwannomas: a systematic review
}

\author{
Kimberley S. Koetsier ${ }^{1}$ (D) Erik F. Hensen ${ }^{1} \cdot$ Rudolf Wiggenraad $^{2,3} \cdot$ Irene M. Lips $^{4}$ • \\ Peter Paul G. van Benthem ${ }^{1}$ • Marco van Vulpen ${ }^{3,4} \cdot$ Helen A. Shih ${ }^{5}$
}

Received: 4 October 2019 / Accepted: 10 December 2019 / Published online: 17 February 2020

(C) The Author(s) 2020

\begin{abstract}
Objective Vestibular schwannomas are benign tumors that are often managed by radiotherapy. Minimizing long-term toxicity is paramount for a population that remains at normal life expectancy and at risk for loss of quality of life for years if not decades. Whereas current radiotherapy standard utilizes photon radiation, proton radiotherapy characteristics may enable a reduction of toxicity by reducing the volume of collateral irradiated healthy tissue. A systematic review was conducted to assess tumor control and short- and long-term sequelae after proton irradiation.

Methods Studies that reported on treatment outcomes of proton radiotherapy in vestibular schwannoma patients were included. Results Five peer-reviewed retrospective series met the inclusion criteria. Quality of the studies varied from low to good. There were 276 unique patients described. Tumor control rates ranged from 85 to 100\% (radiological median follow-up of 2.2-7.4 years). Hearing loss rates, defined as losing Gardner Robertson class I/II hearing, showed an weighted crude average $52 \%$ (depending on follow-up duration). The weighted averages for post-irradiation facial and trigeminal neuropathy were $5 \%$ and $4 \%$, respectively. The risk of neuropathy seems to decrease with lower radiation dosages.

Conclusion Proton irradiation for vestibular schwannomas achieves high tumor control rates, equivalent to photon irradiation. Reported cranial nerve preservation rates vary, partly due to an apparent selection bias with a high percentage of patients with clinical symptoms prior to treatment. Results of cranial nerve function preservation, quality of life, and cognitive functioning are currently insufficiently reported. In addition, advances in proton radiotherapy technology warrant re-evaluation of current techniques and protocols for the management of vestibular schwannomas.
\end{abstract}

Keywords Acoustic neuroma $\cdot$ Neurofibromatosis type $2 \cdot$ Proton therapy $\cdot$ Radiotherapy $\cdot$ Systematic review $\cdot$ Vestibular schwannoma

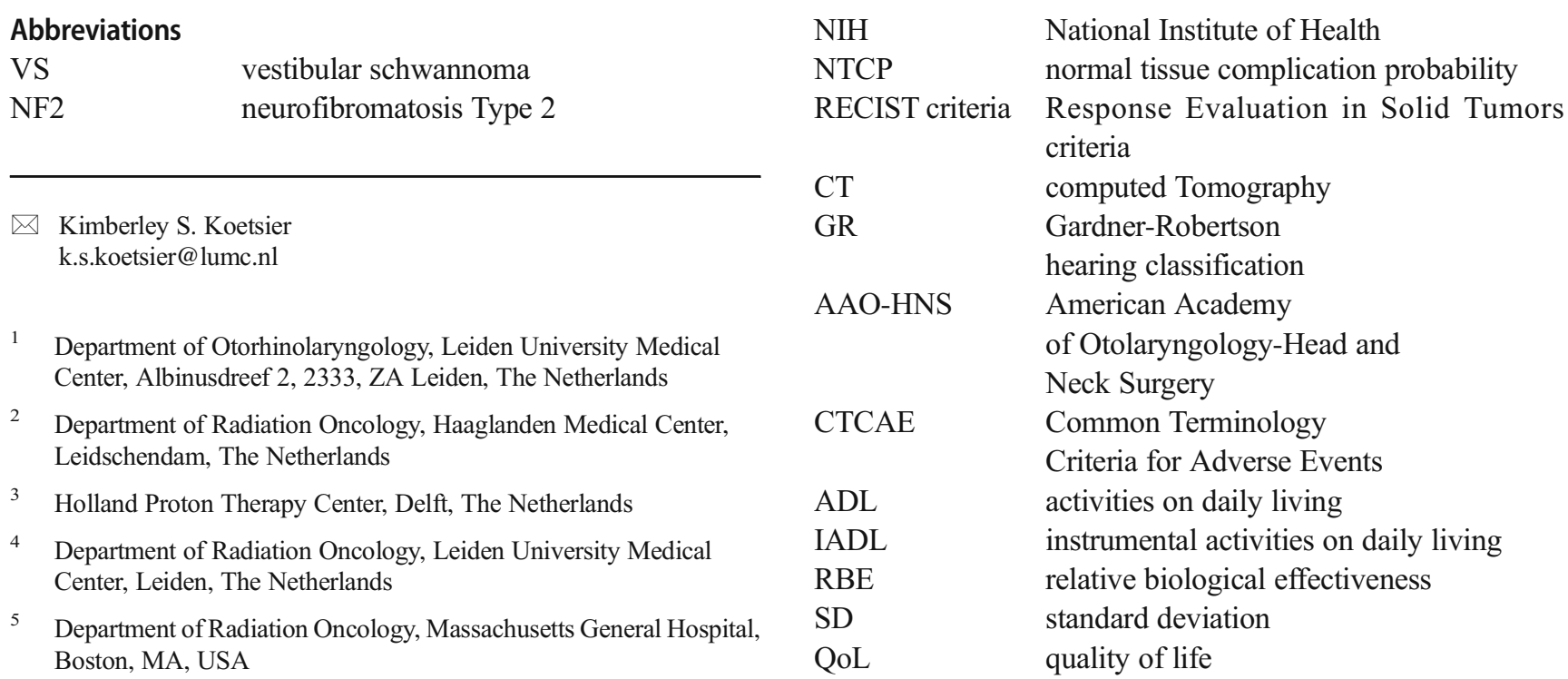




\section{Introduction}

Vestibular schwannomas (VS) are benign skull base tumors with an increasing incidence rate of 34 tumors per million [1]. Although benign, the tumor has the potential of causing serious symptoms, comprising hearing loss, tinnitus, and balance disturbance. Larger tumors may cause facial paresis, facial numbness or pain, elevated intracranial pressure, and compression of the brainstem [2]. Patients suffering from neurofibromatosis type 2 (NF2) and schwannomatosis are predisposed to the development of vestibular schwannomas, usually bilaterally [3]. Treatment options for vestibular schwannoma include surveillance, surgical excision, and radiotherapy. The symptoms and signs induced by the tumoror the therapy - potentially cause a long-lasting impact on quality of life [4-6]. Proton radiotherapy is suggested to minimize the side effects of radiotherapy by reducing the volume of irradiated healthy tissue surrounding the tumor.

While long-term tumor control rates after VS irradiation are approximately $95 \%$, various neurological functions are still threatened by this benign disease or its treatment $[7,8]$. Hearing loss still occurs in approximately half of the patients after photon radiotherapy, a percentage that continues to increase with longer duration of follow-up [7, 9-12]. In addition, radiotherapy confers a risk of increased balance disturbance or dizziness, tinnitus, and trigeminal and facial neuropathy $[13,14]$. Furthermore, the long-term effects of radiotherapy on cognitive functioning are not yet well evaluated, and there is a very small chance of induction of a secondary tumor and sometimes with malignant tumor transformation $[9-12,15,16]$. To minimize these long-term sequelae of radiotherapy, there is a need for an improvement of treatment strategy, especially as the majority of VS patients present in middle age, in the 4 to 6th decade of life, with several decades of expectant survival [17].

In proton therapy, a smaller volume of non-targeted tissue can be irradiated compared to photon therapy [18]. This is a result of the low radiation dose entry and finite Bragg peak, a characteristic radiation dose-deposition peak where protons release most of their radiation energy at the end of its defined path length [19]. There is an absence of dose beyond the Bragg peak, in contrast to photon radiation where x-rays continue to irradiate the tissue beyond the target. In addition, photons have their highest radiation energy deposit shortly after tissue entry, a problem for which many advanced strategies have purposely diffused this entry dose. However, this increases the volume of the brain that receives radiation. In general, the Bragg peak in proton radiotherapy can result in an approximately $50 \%$ dose reduction to the surrounding normal brain tissues $[19,20]$. For vestibular schwannomas, most benefit could potentially be seen in the decrease of (low dose) brain irradiation volume and by using the physical properties of these charged particles to specifically avoid organs at risk (OAR) [21].
As the organs and tissues at risk include the cochlea, the vestibular organ, and the brainstem, reducing radiation dose is relevant. The risk of hearing loss after radiotherapy seems to be dependent on the dose administered to the cochlea, therefore a reduction of cochlear irradiation may result in better long-term hearing [22-29]. The consequences of low-dose brain irradiation are not well understood; however, it is possible that even small amounts of radiation have an impact on the healthy brain tissue $[30,31]$. The trigeminal nerve or the vestibular organ could be additionally spared, which may influence the risk of facial neuralgia, hypoesthesia, and balance disturbance. Although more conformal than photons, the proton beam dose fall off still entails a margin of dose delivered to the normal tissues around a target. Thus, the part of the facial nerve abutting and most adjacent to the tumor does not benefit from the dosimetric benefit of protons over photons; however the more distant parts of the facial nerve and the nuclei may. Moreover, the slightly greater relative biological effectiveness (RBE) of protons to photons is widely accepted as 1.1 , but there are recognized uncertainties in which there could be unrecognized clinical impact [32].

To evaluate tumor control and toxicity of proton radiotherapy in VS patients, a systematic review of the literature was performed to evaluate whether the existing data support that the theoretical advantages of proton therapy translate into clinical benefit.

\section{Material and methods}

\section{Literature search and selection}

A systematic search of the literature was performed in March 2018 using MEDLINE (PubMed), EMBASE, Web of Science, Cochrane Library, ScienceDirect, and GoogleScholar. The research term was formulated with a scientific librarian. The search term is available as supplemental data; it consisted of "proton radiotherapy" and "vestibular schwannomas," as well as more specific search terms, including all VS variants (including "acoustic neuroma" and "cerebellopontine angle tumor"). Translations of VS into German, French, and Dutch were added to the search term. No time frame was used for publication. Reference lists from reviews that came up in the search were screened for additional articles. The inclusion criteria for study selection were (1) patients with a vestibular schwannoma, both sporadic as well as part of NF2; (2) treatment with proton radiotherapy; (3) reported outcomes for tumor control and/or hearing preservation; (4) original data; and (5) a wide range of studies, including meeting abstracts, was accepted to ensure complete literature collection. Exclusion criteria included (1) opinion or editorial paper, (2) within patient radiotherapy technique combinations, (3) animal/laboratory study, (4) studies that only 
reported on meningiomas (NF2), (5) plan comparison studies, and (6) other languages than English, Dutch, French, and German. Two reviewers (EH, KK) independently viewed the abstracts, after which full-text evaluation was performed. Studies with notable similarities were assessed for overlapping datasets; if this was the case, the paper with the largest inclusion was used. This assessment was based on authors, institutions, and data. After full text evaluation, consensus was reached by the two reviewers on article inclusion.

\section{Quality assessment}

The National Institute of Health (NIH) Quality Assessment Tool for case series studies was used to assess the quality of the reports [33]. The assessment for case series was used, as the eligibility criteria for proton irradiation instead of other treatment modalities were unclear, thus making it impossible to conclude a full inclusion of a cohort. To ensure full bias assessment, the list was extended by four questions from the NIH Quality Assessment Tool for Observational Cohort and Cross-Sectional Studies for a more complete assessment (question numbers 8,13, and 14). The final question is an overall rating of the quality of the report, which is either poor, fair, or good. Two researchers (KK, RW) independently assessed the reports, after which consensus was reached on the results of the assessment.

\section{Data extraction}

Data extraction was performed independently by two reviewers (KK, RW). The characteristics of the patient population, intervention, tumor control/size, quality of life, and side effects were tabulated. Side effects included hearing loss, facial and trigeminal nerve impairment, as well as hydrocephalus, death, and a secondary tumor. Tumor control was the primary endpoint and was defined as "not needing salvage treatment" (either surgery or re-irradiation), as this would result in the most reliable measure across the included studies. Because these results were obtained from retrospective reviews, no meta-analysis was performed.

\section{Results}

\section{Literature search}

The search yielded 169 unique records. References of five review reports were scanned, which yielded one extra article for inclusion. Screening abstracts resulted in 25 relevant articles (Fig. 1). Studies reporting on non-clinical outcomes such as treatment planning, dose uncertainty, or comparison studies were excluded (6). Excluded as well were normal tissue complication probability (NTCP) modeling studies (1), side effect case-reports (2), and studies that did not provide details on proton radiotherapy treatment outcome (4). Six reports were excluded because of overlapping data and one because of combining protons and photons as a single treatment. Five articles were deemed eligible after reading full text; details are shown in Table 1.

\section{Quality assessment}

Table 2 shows the results of the quality assessment. Two articles were rated as having a low, two as having a fair, and one as having a good quality. All studies were retrospective and thus inherently limited by study design.

Despite the risk for selection bias in all studies, subjects were overall deemed comparable. Tumor control was clearly defined in all studies; however, this definition was not uniform. Next to the definition of "not requiring salvage treatment," two articles originally reported tumor control by the Response Evaluation in Solid Tumors (RECIST) criteria [34-36]. Some papers also included patients that only had CT imaging available for tumor control follow-up, which can be inconsistent to MRI for volumetric assessment [34, 35, 37].

Hearing assessment was clearly defined in all but one study according to the Gardner-Robertson (GR) hearing classification $[37,38]$. This five-point classification is more often converted into a binary variable for analyses, in which "serviceable hearing" represents a GR classes I or II, and "non-serviceable hearing" represents a score higher than class II. "Serviceable hearing" thus defined includes a wide range of hearing loss categories, from normal hearing to up to $50 \mathrm{~dB}$ hearing loss (pure tone average) and/or 50\% speech discrimination loss. GR classes I and II correspond to the American Academy of Otolaryngology-Head and Neck Surgery (AAOHNS) classes A and B [39]. Although this classification might be easy to use for statistics, it is no longer recommended by the AAO-HNS because the results are not validated. The arbitrary boundaries may cause a dramatic functional difference between two patients in the same classification. The outcomes, therefore, are insufficient to describe the diversity of hearing outcomes encountered clinically [40].

Trigeminal and facial nerve impairment were not clearly defined and have a risk of reporting bias. The HouseBrackmann scale and the Common Terminology Criteria for Adverse Events (CTCAE) 4.0 were used for facial nerve function assessment. The House-Brackmann scale consist of a 6point scale in which grade 1 represents a normal function and grade 6 represents a total paralysis [41]. The CTCAE v4.0 criteria are composed of a grading system in which grade 1 is asymptomatic, defined as only clinical or diagnostic observations which does not require intervention, grade 2 is moderate, which means limiting of instrumental activities on daily living (IADL), and grade 3 is severe, which is limiting of self-care ADL [42]. For trigeminal nerve function, one study provided a 
Fig. 1 Note: This data is mandatory. Please provide.

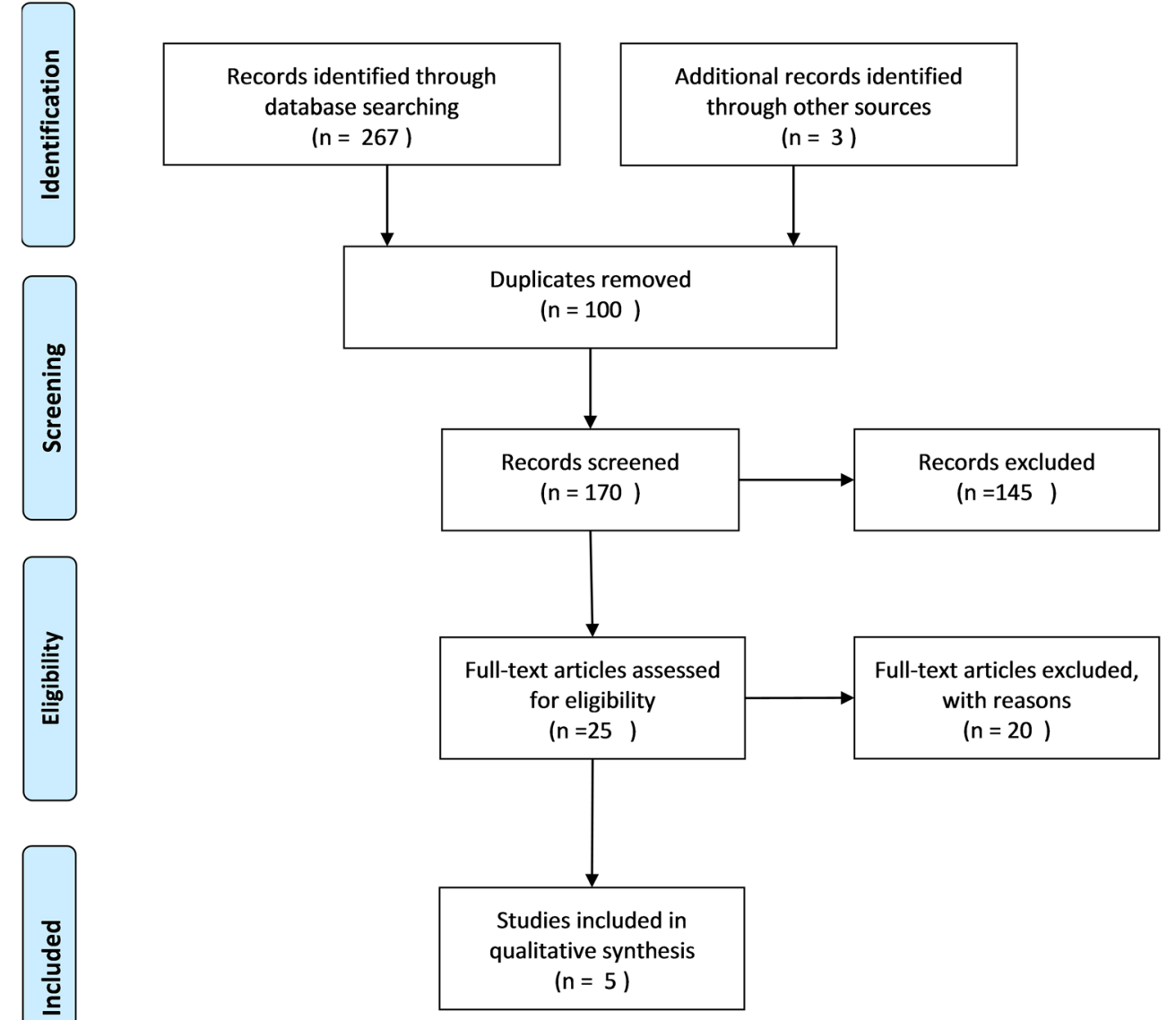

detailed description of the assessment and categorization into "mild" or "significant" impairment [35]. Another report scored the trigeminal neuropathies according to the CTCAE v4.0, scored similarly in degree of impairment to facial nerve dysfunction [35]. The other articles did not mention methodology for trigeminal nerve function assessment. The presence of symptoms such as unsteadiness, vertigo, or tinnitus before irradiation was not consistently described. In addition, cognitive functioning and quality of life were not assessed.

Follow-up was based on the radiological and audiometric assessments measured in years with their corresponding median and range. Recognizing that radiotherapy associated pseudo-progression can evolve over 2-3 years post-treatment, minimum follow-up of at least 3 years was considered ideal [43]. Most reports included patients with shorter follow-up which may affect accurate assessment of tumor control and underestimate long-term sequelae. Hearing loss is dynamic over time and ideally assessed with minimum of 2-year follow-up, although longer follow-up may demonstrate further increase rate of hearing loss [29, 44].

Statistics were overall well described but limited. For example, 95\% confidence intervals were usually lacking. Four articles showed Kaplan-Meier plots, but only one included the loss to follow-up within their plots [37]. One study corrected for confounders by performing a multivariate analysis by logistic and linear regression [34].

\section{Population characteristics}

In all, the 5 retrospective series described 276 unique patients (Table 1). Patient inclusion ranged from 14 to 96 patients. The median age ranged from 56 to 69 years, and the overall age ranged from 20 to 92 years. A variety of tumor assessments were employed, using volumetric or linear diameters. Only one report provided details on tumor aspect (e.g., solid or cystic) or tumor location (e.g., intracanalicular, extracanalicular) [35]. Two reports explicitly stated to have offered proton radiotherapy to patients with larger tumors or to have advised patients to undergo surgery [35, 37]. A large tumor was defined by one paper as a maximum tumor diameter of at least $3 \mathrm{~cm}$ [37]. Another paper included (relatively) large tumors based on photon and proton treatment planning comparison [35].

Prior to treatment, 15-28\% of the included cases underwent a surgical excision of their VS. Gardner-Robertson classes I or II at 


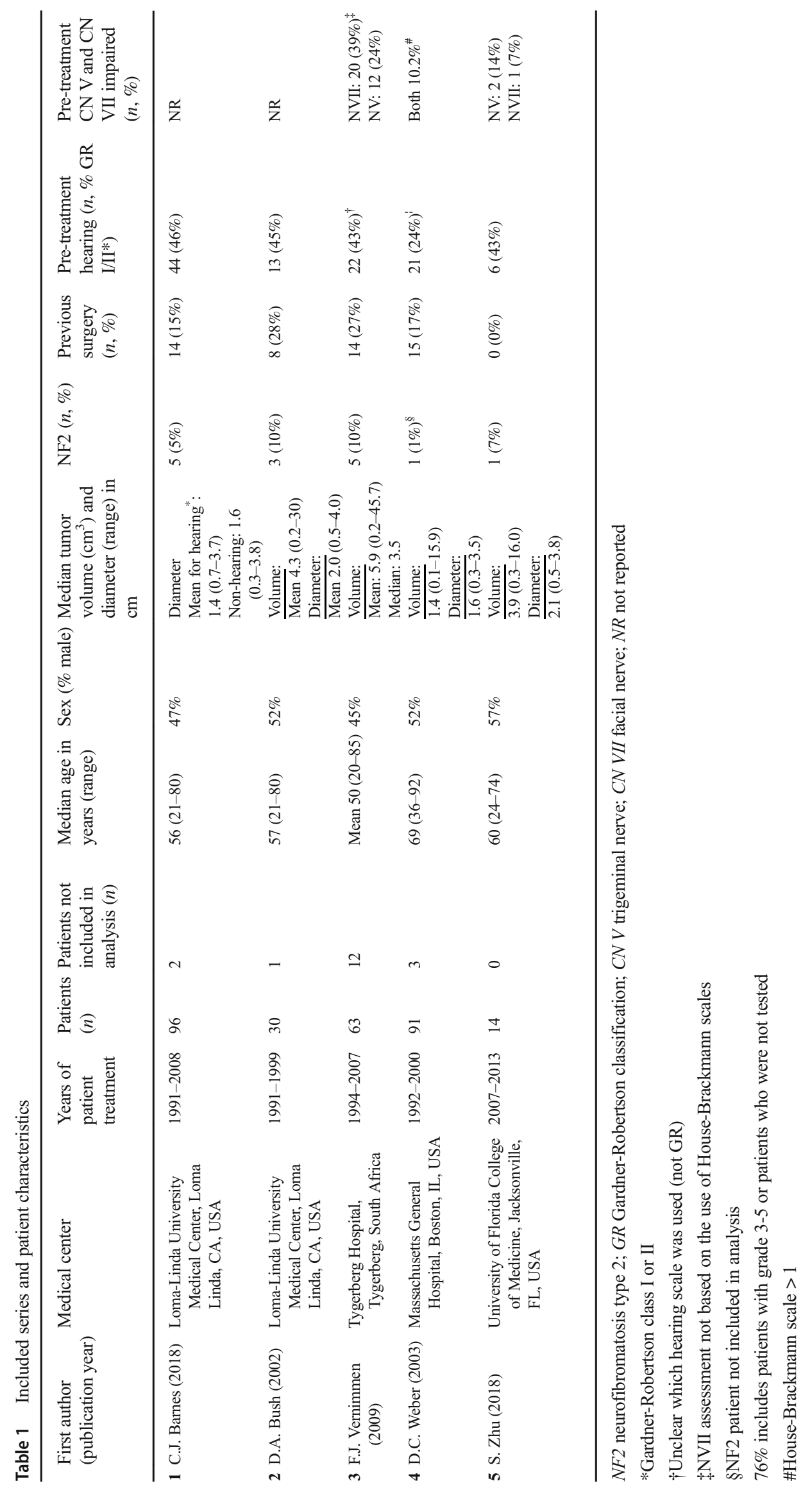


baseline to radiotherapy was present in $24 \%$ to $46 \%$ of patients. NF2 was present between $1 \%$ and $10 \%$ of the included patients.

As standard deviations or standard errors of the population characteristics were not described, population characteristics could not statistically be evaluated by means of an ANOVA analysis.

\section{Intervention characteristics}

Treatment characteristics are shown in Table 3. All studies used passive scattering technology as pencil beam technology was not available at the time the studies were performed. The treatment regimens were heterogenous and included different fractionation strategies, ranging from 1 to 33 fractions. The prescribed total dose ranged as well, from 12 to 60 Gy relative biological effectiveness (RBE), whereas fractionated strategies usually used 1.8$2 \mathrm{~Gy}(\mathrm{RBE})$ per fraction. The prescribed dose has decreased over time: from 60 to $50.4 \mathrm{~Gy}(\mathrm{RBE})$ for fractionated strategies. Single-dose stereotactic radiosurgery in $12 \mathrm{~Gy}(\mathrm{RBE})$ was more often used for smaller tumors, whereas larger tumors were irradiated with fractionated schemes. One center (MGH) employed both single and fractionated proton therapy. Only three articles provided information on planning target volume margins [34, 35, 37]. Two studies included dose constraints for the brainstem (12 Gy(RBE) in proton SRS and $0.1 \mathrm{~cm}^{3}<$ $55 \mathrm{~Gy}(\mathrm{RBE})$ in fractionated proton radiotherapy) [35, 45]. One study aimed at a cochlear dose under $36 \mathrm{~Gy}(\mathrm{RBE})$, and two studies mentioned a lower prescribed dose for patients with good hearing [34, 35, 46]. For those studies that comment on image guidance, either fiducial markers or bony landmarks were used for anatomical confirmation of treatment set up. One study irradiated their patients on an adjustable chair [37].

\section{Tumor control and size}

The overall tumor control rates varied from $85 \%$ to $100 \%$, with a radiological median follow-up ranging from 2.2 to 7.4 years (Table 4). The unweighted average crude tumor control rate was $94 \%$ (standard deviation 5.6\%); this was

Table 2 Quality assessment

\begin{tabular}{|c|c|c|c|c|c|}
\hline Criteria & $\begin{array}{l}\text { D.A. } \\
\text { Bush } \\
\text { et al. } \\
(2002)\end{array}$ & $\begin{array}{l}\text { F.J.A.I. } \\
\text { Vernimmen } \\
(2008)\end{array}$ & $\begin{array}{l}\text { D.C. Weber } \\
\text { et al. (2003) }\end{array}$ & $\begin{array}{l}\text { S. Zhu } \\
\text { et al. } \\
(2018)\end{array}$ & $\begin{array}{l}\text { C.J. Barnes } \\
\text { et al. (2018) }\end{array}$ \\
\hline 1. Was the study question or objective clearly stated? & Y & $\mathrm{Y}$ & Y & Y & $\mathrm{Y}$ \\
\hline $\begin{array}{l}\text { 2. Was the study population clearly and fully described, including a case } \\
\text { definition? }\end{array}$ & Y & Y & Y & Y & $\mathrm{Y}$ \\
\hline 3. Were the cases consecutive? & $\mathrm{CD}$ & $\mathrm{N}$ & $\mathrm{Y}$ & $\mathrm{CD}$ & $\mathrm{Y}$ \\
\hline 4. Were the subjects comparable? & $\mathrm{Y}$ & $\mathrm{N}$ & $\mathrm{Y}$ & $\mathrm{Y}$ & $\mathrm{Y}$ \\
\hline 5. Was the intervention clearly described? & $\mathrm{N}$ & $\mathrm{N}$ & $\mathrm{Y}$ & $\mathrm{Y}$ & $\mathrm{Y}$ \\
\hline $\begin{array}{l}\text { 6. Were the outcome measures clearly defined, valid, reliable, and implemented } \\
\text { consistently across all study participants? }\end{array}$ & $\mathrm{Y}^{\dagger}$ & $\mathrm{N}^{\ddagger}$ & $\mathrm{Y}$ & $\mathrm{Y}^{\S}$ & $\mathrm{Y}^{\dagger}$ \\
\hline 7. Was the length of follow-up adequate? & $\mathrm{N}$ & $\mathrm{Y}$ & $\mathrm{Y}$ & $\mathrm{Y}$ & $\mathrm{Y}$ \\
\hline 8. Were the statistical methods well-described? & $\mathrm{Y}$ & $\mathrm{Y}$ & $\mathrm{Y}$ & $\mathrm{Y}$ & $\mathrm{Y}$ \\
\hline 9. Were the results well-described? & $\mathrm{N}$ & Y & Y & Y & $\mathrm{Y}$ \\
\hline \multicolumn{6}{|l|}{ Additional } \\
\hline $\begin{array}{l}\text { 10. For exposures that can vary in amount or level, did the study examine } \\
\text { different levels of the exposure as related to the outcome (e.g., categories of } \\
\text { exposure, or exposure measured as continuous variable)? }\end{array}$ & $\mathrm{N}$ & $\mathrm{N}$ & $\mathrm{Y}$ & $\mathrm{N}$ & $\mathrm{Y}$ \\
\hline 11. Was loss to follow-up after baseline $20 \%$ or less? & $\mathrm{Y}$ & $\mathrm{Y}$ & $\mathrm{Y}$ & $\mathrm{Y}$ & $\mathrm{Y}$ \\
\hline $\begin{array}{l}\text { 12. Were key potential confounding variables measured and adjusted } \\
\text { statistically for their impact on the relationship between exposure(s) and } \\
\text { outcome(s)? }\end{array}$ & $\mathrm{N}$ & $\mathrm{N}$ & $\mathrm{N}$ & $\mathrm{N}$ & $\mathrm{Y}$ \\
\hline Quality rating & Low & Low & Fair & Fair & Good \\
\hline
\end{tabular}

Abbreviations: Y, yes; N, no; NR, not reported; CD, cannot determine; NA, not applicable

*Except for vestibular schwannoma treated by proton radiotherapy, not other in or exclusion criteria were mentioned

$\dagger$ Facial and trigeminal impairment measures were not defined

tCranial nerve function scale is not validated, audiometry, and trigeminal nerve impairment measures were not defined

$\S$ Facial and trigeminal assessment partially through telephone surveys 
Table 3 Treatment characteristics

\begin{tabular}{|c|c|c|c|c|c|c|c|c|}
\hline & $\begin{array}{l}\text { First author } \\
\text { (publication year) }\end{array}$ & $\begin{array}{l}\text { Type of proton } \\
\text { therapy }\end{array}$ & $\begin{array}{l}\text { Number } \\
\text { of fractions }\end{array}$ & $\begin{array}{l}\text { Prescribed dose } \\
\text { in Gy(RBE) }\end{array}$ & $\begin{array}{l}\text { Max. dose } \\
\text { in Gy(RBE) }\end{array}$ & $\begin{array}{l}\text { Min. dose } \\
\text { in } \mathrm{Gy}(\mathrm{RBE})\end{array}$ & $\begin{array}{l}\text { Specifications } \\
\text { isodose }\end{array}$ & $\begin{array}{l}\text { Planning target } \\
\text { volume margin }\end{array}$ \\
\hline 1 & C.J. Barnes (2018) & Passive scatter & $28-33$ & $50.4,54$, or 59.4 & NR & NR & NR & $2-3 \mathrm{~mm}$ \\
\hline 2 & D.A. Bush (2002) & Passive scatter & $30-33$ & 54 or 60 & NR & NR & $100 \% *$ & NR \\
\hline 3 & F.J. Vernimmen (2009) & Passive scatter & 3 & Median 26 (range 19.8-41.9) & NR & Mean 21.4 (range 14-33) & $\begin{array}{l}85 \% \text { (median) } \\
\text { range } 65-90 \%\end{array}$ & $0 \mathrm{~mm}$ \\
\hline 4 & D.C. Weber (2003) & Passive scatter & 1 & Median 12 (range 10-18) & $\begin{array}{l}17.1 \\
\text { (median) }\end{array}$ & $\begin{array}{l}12 \\
\text { (median) }\end{array}$ & $70 \%(70-108 \%)$ & NR \\
\hline 5 & S. Zhu (2018) & Passive scatter & 28 & 50.4 & NR & NR & $100 \%$ & $5 \mathrm{~mm}$ \\
\hline
\end{tabular}

RBE, relative biological effectiveness

*Estimated from figure

95\% when weighted for sample size. This was irrespective of pre-treatment characteristics. Pseudo-progression, a temporary increase in tumor volume in response to radiation, could influence the accuracy of reported tumor control rates. These patients are more likely to require surgical excision of the tumor in large tumors because of symptomatic mass effect and/or obstructive hydrocephalus. For the patients not achieving tumor control, the median time to salvage treatment was 12 months. In all, 8 out of 13 patients were treated $\leq 2$ years after irradiation. Two reports explicitly stated to have offered proton radiotherapy to patients with larger tumors or to have advised patients to undergo surgery $[35,37]$.

Tumor size increase was reported in $0-12 \%$ of the irradiated patients. A decrease in tumor size was reported for $23 \%$ to $69 \%$ of the patients at median follow-up between 2.2 and 7.4 years. A single-fraction SRS study showed both the highest increase and subsequent decrease rate of tumor volume [45]. Furthermore, the decrease of tumor size might be dose dependent, as another study reported tumor shrinkage rate of 50\% after $59.4 \mathrm{~Gy}(\mathrm{RBE})$, in comparison to $44 \%$ and $39 \%$ for 54 and $50.4 \mathrm{~Gy}(\mathrm{RBE})$, respectively. The median follow-up durations were 6.6, 7.4, and 4.3 years, respectively [34]. No clear association of follow-up time or fractionation scheme to change in tumor size was seen in the current limited results.

\section{Neurofibromatosis type 2}

NF2 was present in 15 patients (between $1 \%$ and $10 \%$ of the included patients). The NF2-related tumor outcomes were included in the overall analyses in all papers, expect for one [45]. The clinical outcomes for the included patient with NF2 were only explicitly mentioned by one paper: in their patient, the tumor volume increased from 2.1 to $4.0 \mathrm{cc}$ (did not require salvage treatment), with GR class II hearing after a median follow-up of 2.2 years. All other publications did not specify outcomes for NF2 patients.

\section{Hearing loss}

Table 5 shows the toxicity results, including hearing loss. The reported proportion of patients suffering from post-irradiation hearing loss ranged from $21 \%$ to $78 \%$, with an weighted crude average hearing loss rate of $52 \%$. Average dosages to the cochlea were not mentioned. Two studies reported on hearing loss between GR classifications: out of eight patients with GR class I hearing prior to treatment, one remained in that hearing class. There was a marked difference between short-term and long-term hearing loss rates, i.e., short-term hearing loss (calculated by using 2-year follow-up hearing outcomes if available) was found in $24 \%$, while the long-term hearing loss (using 5-year follow-up data) increased to $68 \%$. Prior to treatment, $15-28 \%$ of patients underwent a surgical excision of their VS, which likely decreased the number of hearing patients before radiation treatment.

Shunting for an acute hydrocephalus was necessary in three patients in one study and not mentioned in the other reports [45].

The occurrence of hearing loss after proton irradiation seems to be dependent of several factors in the included studies. First, hearing loss increases with time. Almost all studies with longterm follow-up demonstrate that longer follow-up results in increased severity of hearing loss [44]. This is in keeping with known other late effects of radiotherapy that gradually increase with time. Second, the risk of hearing loss is dose dependent, as one study showed a trend toward better preservation of hearing after reducing the total dosage from 54 to $50.4 \mathrm{~Gy}(\mathrm{RBE})$ [34]. Further details of total dose, fractionation, and radiation sensitivity to specific structures such as the cochlea are less well described: A study that used SRS described the highest hearing loss rate (78\%) after a 5-year follow-up period [45]. They included 21 patients; however, the median audiometric follow-up duration was 2.7 years, thus making it likely that the 5-year follow-up group was much smaller. Patient age may be associated with increased risk for hearing loss with radiation treatment. Barnes et al. reported a much lower hearing loss rate of $43 \%$ than Weber et al. of $67 \%$; however there was a difference in median age of 56 vs 69 years, respectively [34, 45]. Lastly, tumor size may be of influence with increased tumor size 


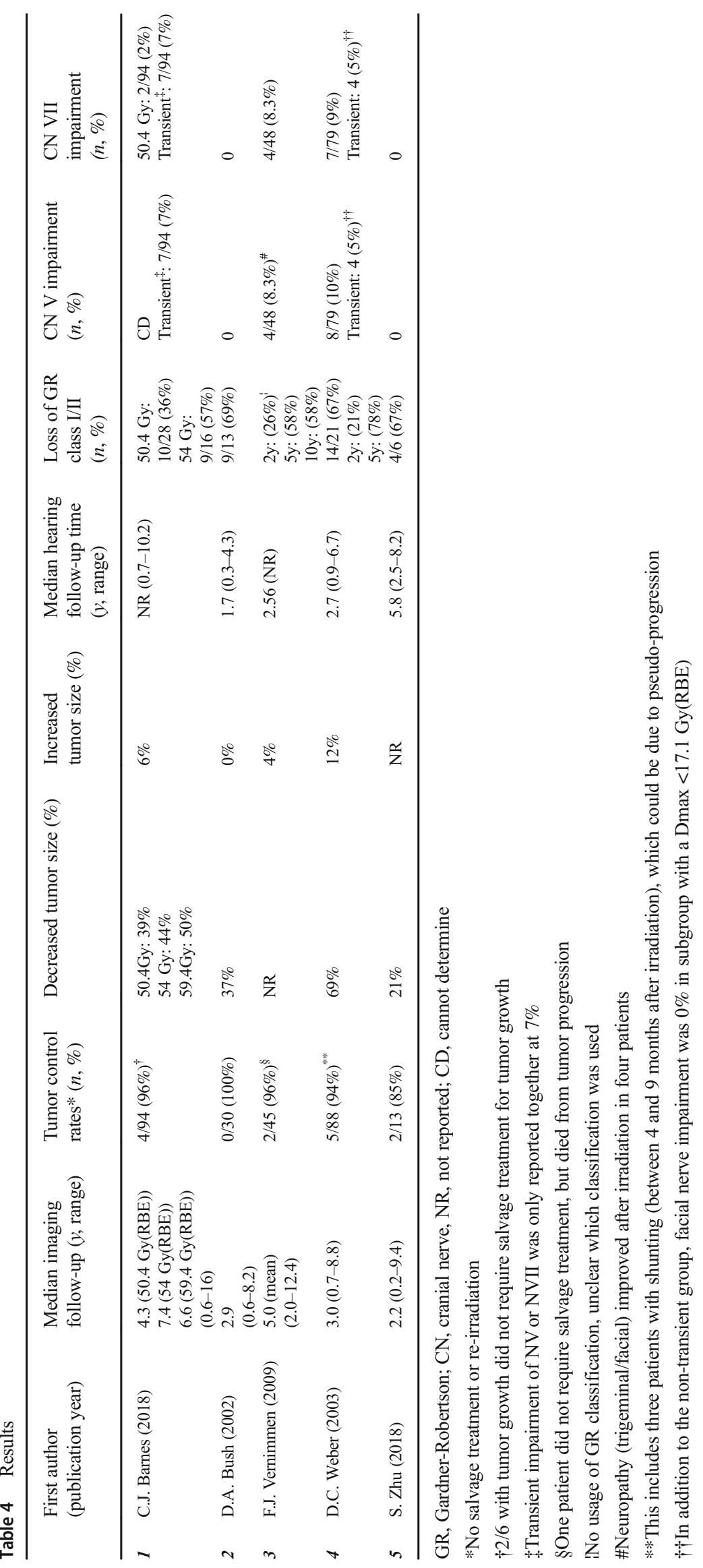


Table 5 Overview of reported complications after proton radiotherapy

\begin{tabular}{llll}
\hline & \multicolumn{2}{l}{ Outcome } & \\
\cline { 2 - 4 } Toxicity & Weighted average & Range & Toxicity measure \\
\hline Facial paresis & $5 \%$ & $0-9 \%$ & House-Brackmann scale or CTCAE v 4.0 \\
Trigeminal neuropathy & $4 \%$ & $0-10 \%$ & CTCAE v 4.0 or rated as mild/significant \\
Hydrocephalus & $1 \%$ & $0-3.4 \%$ & Ventriculoperitoneal shunting for hydrocephalus \\
Hearing loss & $52 \%$ & $21-78 \%$ & Loss of GR class I/II \\
\hline
\end{tabular}

CTCAE, Common Terminology Criteria for Adverse Events; GR, Gardner-Robertson hearing classification associated with increased hearing loss. In one study, hearing loss in patients with small $(<1.5 \mathrm{~cm})$ versus large $(>1.5 \mathrm{~cm})$ tumors was $26 \%$ versus $80 \%$, respectively, which was significant on multivariate analysis [34].

\section{Facial and trigeminal nerve impairment}

Facial and trigeminal nerve impairment due to radiotherapy may occur transiently or permanently and may be partial or total. Trigeminal nerve impairment occurred in $0-10 \%$ of patients irradiated with proton radiotherapy (weighted average $4 \%$ ). It is unclear whether this consisted of trigeminal neuralgia, paraesthesia, or only hypoesthesia. Facial nerve impairment occurred in 0 $9 \%$ (weighted average of 5\%). These neuropathies seemed to occur less frequent in treatments with lower dosages [34, 45].

Both cranial nerves seem to be impaired more often after single-fraction or hypofractionation (three fractions) schemes, although this could be due to reporting bias or small sample sizes (Table 4). Surgery before radiotherapy, prescribed radiotherapy dose and maximum radiotherapy dose were not associated with development of post-treatment neuropathy.

Of note, the reported prevalence of trigeminal nerve impairment before proton radiotherapy that was initiated was rather high with a trigeminal nerve neuropathy in 10-24\% and a facial paresis in 7-39\% (Table 1). In general, cranial nerves affected prior to intervention are prone to further radiation damage. This may indicate a selection bias in these reports, possibly resulting in overestimation of cranial nerve injury due to proton radiotherapy.

\section{Mortality and radiation-induced tumors}

No radiation-induced tumors, benign or malignant, were reported after proton radiotherapy. One patient died due to tumor size progression [37]. No other treatment-related mortalities were reported.

\section{Quality of life}

A search for quality of life (QoL) or QoL-related issues yielded no results. Moreover, no studies reported on tinnitus, dizziness, unsteadiness, or cognitive functioning outcomes.

\section{Discussion}

This systematic review aimed to assess the tumor control and toxicity rates of proton radiotherapy for vestibular schwannomas. Five retrospective reviews were included. The quality assessment showed two articles as having a low, two as having a fair, and one as having a good quality. Only one paper corrected for confounders and only three analyzed the results in subgroups. All studies were retrospective in design, with inherent limitations of patient selection and outcomes reporting bias. The quality assessment also showed a risk of attrition bias because of the non-consecutive inclusion. Only a small percentage of the patients was reported as lost to follow-up; however the follow-up duration has been varied.

Despite this study's limitations, VS tumor control rate after proton irradiation, defined as not requiring salvage treatment after irradiation, was a reliable and comparable outcome. It showed similar tumor control rates to other radiotherapeutic modalities (92-100\% for photons). A systematic review on photon radiosurgery and fractionated radiotherapy reported a tumor control rate of $95 \%$ for both modalities [7]. No published full reports described 10-year follow-up results, but one conference abstract did approximate this that was excluded for overlapping data $[28,40]$. With a median follow-up time of 9.5 years for 52 patients, tumor control was $98 \%$. The occurrence of pseudo-progression may have played a role in the tumor control results, as large tumors were also included in the reviewed studies, and pseudo-progression is more likely to necessitate symptom management in large tumors [35, 37]. Indeed, most patients requiring salvage treatment were treated within 2 years after their radiation treatment raising the question on whether these were true treatment failures. Additional factors that influence tumor control are prior surgical excision and explicitly offering proton radiotherapy to patients with larger tumors surgery. These conditions harbor intrinsic selection bias of patients with larger tumors that are subsequently referred for proton therapy, for example, to minimize collateral brain irradiation. This could negatively influence tumor control rates and risk for treatment-related symptoms.

NF2 patients remain a unique subset of VS patients with suspected lower rates of tumor control after radiation therapy. 
A recent systematic review reported a mean 5-year control rate of $75 \%$ after stereotactic radiosurgery in NF2 patients, which is notably lower than for sporadic vestibular schwannoma patients [47]. Here, our data does not show a decreased efficacy of proton irradiation for NF2-associated VS in the aggregate small group of 15 patients identified. However, with known genetic and clinical differences in NF2 patients as compared to sporadic VS patients, NF2 patients should be separately analyzed to better elucidate potential differences in efficacy of proton therapy between sporadic and NF2 tumors.

The toxicity profile of proton radiotherapy is currently difficult to evaluate aside from no unexpected adverse effects. Assessments are further limited by the use of increasingly antiquated scattering proton technology and higher radiation doses than currently commonly used. In addition, studies suffer from selection bias and varying reporting consistency. For example, hearing loss is reported by a binary version of the Gardner-Robertson classification which is deemed insensitive as per AAO-HNS recommendation [40]. Regardless of the classification used, hearing loss occurs frequently after radiotherapy in VS patients. The crude average hearing loss rate was $24 \%$ and $68 \%$ for a 2 - and 5-year follow-up period, respectively. This seems to be higher than reported in a systematic review on hearing loss after photon radiotherapy (42\% at 4-year follow up, range: 14-92\%). Previous studies have shown cochlear dose to be related to hearing loss progression [23-29, ]. While none of the included studies provided information on the cochlear doses within their study population, one article did state that efforts were made to reduce the dose to the cochlea to $36 \mathrm{~Gy}(\mathrm{RBE})$ (while maintaining target coverage) [35]. The reported occurrence and severity of hearing loss after proton irradiation are probably dependent on several other factors too: the duration of the follow-up, the radiation dose to various structures (brainstem and/or cochlear nerve), the fractionation strategy, tumor size, the patient's age, and other comorbidities with possible associated radiation sensitivities such as vascular diseases. In addition, the occurrence of pseudo-progression is previously suggested to be of influence on hearing loss as well [48]. In this study, we find evidence for increased post-irradiation hearing loss in patients with a longer follow-up and those receiving a higher total irradiation dose; however the observed differences are based upon a small sample and not surprising without significant difference.

The reported prevalence of facial and trigeminal nerve impairment due to proton radiotherapy ranged significantly $(0-$ $10 \%$ and $0-9 \%$, respectively). The high pre-irradiation prevalence of trigeminal and facial neuropathies in some reports may reflect a selection bias, leading to possible overestimation of proton therapy-induced injury. Although most articles included a standardized follow-up protocol comprising audiometry and MR imaging, assessment of trigeminal and facial nerve function was less consistent. In this study, there is low evidence for a higher incidence of facial and trigeminal neuropathy after single-fraction proton radiosurgery. Other reported predictive factors for facial and trigeminal neuropathy include prior vestibular schwannoma surgery, large tumor size, a higher total radiation dose, advanced patient age, and preexisting neuropathy [49-51].

Other possible side effects of radiotherapy in vestibular schwannoma patients, such as unsteadiness, vertigo and tinnitus, and long-term sequelae such as impact on cognitive functioning, could not be assessed in this review because of insufficient reporting. These outcomes - which are difficult to measure - could be assessed by disease-specific QoL surveys. However, these are lacking for comparison of these complaints to other treatment modalities. Quality of life is arguably the most important outcome and key factor when weighing between therapeutic modalities for vestibular schwannoma patients. Potential effects of the dosimetric differences to the healthy brain tissue are also missing from this review and could potentially be assessed through QoL surveys and/or neurocognitive testing. As a consequence, an accurate inference of QoL could not be determined by the available data. The necessary data does not yet exist and will be imperative to future guidance of best patient care.

Individualized strategy is best for each vestibular schwannoma patient. These range from observation to a variety of radiotherapy options to a variety of surgical approaches. The challenge is to identify those subgroups that would benefit most from a specific treatment, including the option of proton radiotherapy. The rationale for choosing proton radiotherapy over other radiotherapy modalities is the possible reduction of side effects and sequelae induced by the radiotherapy, such as hearing loss, possibly impaired cognitive functioning, and cranial nerve function loss. Theoretically, reducing the amount of irradiation of surrounding tissues by using proton radiotherapy could result in improved cognitive functioning, decreased risk of cranial nerve neuropathies, and a decreased risk of secondary tumor induction. However, while tumor control rates of proton radiotherapy are comparable to other radiotherapeutic modalities, there is currently insufficient clinical evidence to confirm that proton radiotherapy incurs less or less severe side effects than photon radiotherapy in vestibular schwannoma patients, both in the short and long term. At the moment, it is unclear whether this is due to comparable toxicity profiles, to the limited number and quality of the reports on proton radiotherapy in vestibular schwannoma patients, or to the fact that most reviewed articles did not report on the latest proton radiotherapy techniques.

Acknowledgments The authors thank Jan W. Schoones, librarian at the Walaeus Library, (Leiden University Medical Center) for his help on the search strategy. 


\section{Compliance with ethical standards}

Conflict of interest The authors declare that they have no conflict of interest.

Ethical approval This article does not contain any studies with human participants or animals performed by any of the authors.

Open Access This article is licensed under a Creative Commons Attribution 4.0 International License, which permits use, sharing, adaptation, distribution and reproduction in any medium or format, as long as you give appropriate credit to the original author(s) and the source, provide a link to the Creative Commons licence, and indicate if changes were made. The images or other third party material in this article are included in the article's Creative Commons licence, unless indicated otherwise in a credit line to the material. If material is not included in the article's Creative Commons licence and your intended use is not permitted by statutory regulation or exceeds the permitted use, you will need to obtain permission directly from the copyright holder. To view a copy of this licence, visit http://creativecommons.org/licenses/by/4.0/.

\section{References}

1. Reznitsky MSPM, West N, Stangerup SE, Cayé-Thomasen P (2019) Epidemiology of vestibular schwannomas - prospective 40-year data from an unselected national cohort. Clin Epidemiol 11:971-986

2. Matthies C, Samii M (1997) Management of 1000 vestibular schwannomas (acoustic neuromas): clinical presentation. Neurosurgery 40(1):1-9 discussion -10

3. Evans DG. Neurofibromatosis type 2. (0072-9752 (Print))

4. Soulier G, van Leeuwen BM, Putter H, Jansen JC, Malessy MJA, van Benthem PPG, van der Mey AGL, Stiggelbout AM (2017) Quality of life in 807 patients with vestibular schwannoma: comparing treatment modalities. Otolaryng Head Neck 157(1):92-98

5. Robinett ZN, Walz PC, Miles-Markley B, Moberly AC, Welling DB (2014) Comparison of long-term quality-of-life outcomes in vestibular schwannoma patients. Otolaryng Head Neck. 150(6): 1024-1032

6. Vannson N, James C, Fraysse B, Strelnikov K, Barone P, Deguine O et al (2015) Quality of life and auditory performance in adults with asymmetric hearing loss. Audiol Neurootol 20(Suppl 1):38-43

7. Persson O, Bartek J, Ben Shalom N, Wangerid T, Jakola AS, Forander P (2017) Stereotactic radiosurgery vs. fractionated radiotherapy for tumor control in vestibular schwannoma patients: a systematic review. Acta Neurochir 159(6):1013-1021

8. Murphy ES, Suh JH (2011) Radiotherapy for vestibular schwannomas: a critical review. Int J Radiat Oncol Biol Phys 79(4):985-997

9. Gan HK, Bernstein LJ, Brown J, Ringash J, Vakilha M, Wang L et al (2011) Cognitive functioning after radiotherapy or chemoradiotherapy for head-and-neck Cancer. Int J Radiat Oncol Biol Phys 81(1):126-134

10. Gondi V, Hermann BP, Mehta MP, Tome WA (2013) Hippocampal dosimetry predicts neurocognitive function impairment after fractionated stereotactic radiotherapy for benign or low-grade adult brain tumors. Int J Radiat Oncol Biol Phys 85(2):348-354

11. Hansen CC, Smith JB, Mohamed ASR, Mulcahy CF, Wefel JS, Hutcheson KA et al (2017) Cognitive function and patientreported memory problems after radiotherapy for cancers at the skull base: a cross-sectional survivorship study using the telephone interview for cognitive status and the MD Anderson symptom inventory-head and neck module. Head Neck J Sci Spec 39(10): 2048-2056

12. Hsiao KY, Yeh SA, Chang CC, Tsai PC, Wu JM, Gau JS (2010) Cognitive function before and after intensity-modulated radiation therapy in patients with nasopharyngeal carcinoma: a prospective study. Int J Radiat Oncol Biol Phys. 77(3):722-726

13. Lee TF, Yeh SA, Chao PJ, Chang L, Chiu CL, Ting HM et al (2015) Normal tissue complication probability modeling for cochlea constraints to avoid causing tinnitus after head-and-neck intensitymodulated radiation therapy. Radiat Oncol 10:194

14. Kim G, Hullar TE, Seo JH 2019 Comparison of balance outcomes according to treatment modality of vestibular schwannoma. Laryngoscope.

15. Pollock BE, Link MJ, Stafford SL, Parney IF, Garces YI, Foote RL (2017) The risk of radiation-induced tumors or malignant transformation after single-fraction intracranial radiosurgery: results based on a 25year experience. Int J Radiat Oncol Biol Phys 97(5):919-923

16. Shin M, Ueki K, Kurita H, Kirino T (2002) Malignant transformation of a vestibular schwannoma after gamma knife radiosurgery. Lancet. 360(9329):309-310

17. Propp JM, McCarthy BJ, Davis FG, Preston-Martin S (2006) Descriptive epidemiology of vestibular schwannomas. NeuroOncology. 8(1):1-11

18. Weber DC, Ares C, Lomax AJ, Kurtz JM (2006) Radiation therapy planning with photons and protons for early and advanced breast cancer: an overview. Radiat Oncol 1:22

19. DeLaney TF (2018) Charged issues: particle radiation therapy. Semin Radiat Oncol 28(2):75-78

20. Arvold ND, Niemierko A, Broussard GP, Adams J, Fullerton B, Loeffler JS et al (2012) Projected second tumor risk and dose to neurocognitive structures after proton versus photon radiotherapy for benign meningioma. Int J Radiat Oncol Biol Phys 83(4):e495-e500

21. Bolsi A, Fogliata A, Cozzi L (2003) Radiotherapy of small intracranial tumours with different advanced techniques using photon and proton beams: a treatment planning study. Radiother Oncol 68(1):1-14

22. Bennion NR, Nowak RK, Lyden ER, Thompson RB, Li S, Lin C (2016) Fractionated stereotactic radiation therapy for vestibular schwannomas: dosimetric factors predictive of hearing outcomes. Pract Radiat Oncol 6(5):E155-EE62

23. Ma LJ, Braunstein SE, Theodosopoulos PV, McDermott MW, Sneed PK (2017) Inherent functional dependence among cochlear dose surrogates for stereotactic radiosurgery of vestibular schwannomas. Pract Radiat Oncol. 7(1):E1-E7

24. Mujica-Mota M, Waissbluth S, Daniel SJ (2013) Characteristics of radiation-induced sensorineural hearing loss in head and neck cancer: a systematic review. Head Neck J Sci Spec 35(11):1662-1668

25. Pan SY, Liu SA, Sun MH, Tsou HK, Lee SD, Chen YJ et al (2017) Outcome of hearing preservation related to tumor morphologic analysis in acoustic neuromas treated by gamma knife radiosurgery. Radiat Oncol 12

26. Bhandare N, Jackson A, Eisbruch A, Pan CC, Flickinger JC, Antonelli $\mathrm{P}$ et al (2010) Radiation therapy and hearing loss. Int J Radiat Oncol Biol Phys. 76(3):S50-SS7

27. Brown M, Ruckenstein M, Bigelow D, Judy K, Wilson V, AlonsoBasanta $M$ et al (2011) Predictors of hearing loss after gamma knife radiosurgery for vestibular schwannomas: age, cochlear dose, and tumor coverage. Neurosurgery. 69(3):605-613

28. Lin RH, Wang TC, Lin CD, Lin HL, Chung HK, Wang CY et al (2017) Predictors of hearing outcomes following low-dose stereotactic radiosurgery in patients with vestibular schwannomas: a retrospective cohort review. Clin Neurol Neurosur 162:16-21

29. van Linge A, van Os R, Hoekstra N, Heijmen B, Stienstra L, Dallenga A et al (2018) Progression of hearing loss after LINACbased stereotactic radiotherapy for vestibular schwannoma is 
associated with cochlear dose, not with pre-treatment hearing level. Radiat Oncol 13(1):253

30. Douw L, Klein M, Fagel SSAA, van den Heuvel J, Taphoorn MJB, Aaronson NK et al (2009) Cognitive and radiological effects of radiotherapy in patients with low-grade glioma: long-term followup. Lancet Neurol 8(9):810-818

31. Parihar VK, Limoli CL (2013) Cranial irradiation compromises neuronal architecture in the hippocampus. P Natl Acad Sci USA 110(31):12822-12827

32. Paganetti H, Niemierko A, Ancukiewicz M, Gerweck LE, Goitein M, Loeffler JS et al (2002) Relative biological effectiveness (RBE) values for proton beam therapy. Int J Radiat Oncol Biol Phys 53(2): 407-421

33. NIH National Heart LaBI. Study Quality Assessment Tools

34. Barnes CJ, Bush DA, Grove RI, Loredo LN, Slater JD (2018) Fractionated proton beam therapy for acoustic neuromas: tumor control and hearing preservation. Int J Part Ther 4(4):28-36

35. Zhu S, Rotondo R, Mendenhall WM, Dagan R, Lewis D, Huh S, Knox G, Tavaniepour D, Sandhu S, Rutenberg MS (2018) Longterm outcomes of fractionated stereotactic proton therapy for vestibular schwannoma: A case series. Int J Part Ther 4(4):37-46

36. Eisenhauer E, Therasse P, Bogaerls J, Schwartz L, Sargent D, Ford $R$ et al (2008) New response evaluation criteria in solid tumors: revised RECIST guideline version 1.1. Eur J Cancer 6(12):13

37. Vernimmen FJ, Mohamed Z, Slabbert JP, Wilson J (2009) Longterm results of stereotactic proton beam radiotherapy for acoustic neuromas. Radiother Oncol 90(2):208-212

38. Gardner G, Robertson JH (1988) Hearing preservation in unilateral acoustic neuroma surgery. Ann Oto Rhinol Laryn 97(1):55-66

39. Monsell EM, Balkany TA, Gates GA, Goldenberg RA, Meyerhoff WL, House JW (1995) Committee on hearing and equilibrium guidelines for the evaluation of hearing preservation in acoustic neuroma (vestibular Schwannoma). Otolaryng Head Neck. 113(3):179-180

40. Gurgel RK, Jackler RK, Dobie RA, Popelka GR (2012) A new standardized format for reporting hearing outcome in clinical trials. Otolaryng Head Neck. 147(5):803-807

41. House JW, Brackmann DE (1985) Facial-nerve grading system. Otolaryng Head Neck 93(2):146-147
42. Diagnosis NNCIDoCT. Common Terminology Criteria for Adverse Events (CTCAE) [Available from: https://ctep.cancer.gov/ protocolDevelopment/electronic applications/ctc.htm

43. Hayhurst C, Zadeh G (2012) Tumor pseudoprogression following radiosurgery for vestibular schwannoma. Neuro-Oncology. 14(1):87-92

44. Coughlin AR, Willman TJ, Gubbels SP (2018) Systematic review of hearing preservation after radiotherapy for vestibular schwannoma. Otol Neurotol 39(3):273-283

45. Weber DC, Chan AW, Bussiere MR, Harsh GR, Ancukiewicz M, Barker FG et al (2003) Proton beam radiosurgery for vestibular schwannoma: tumor control and cranial nerve toxicity. Neurosurgery. 53(3):577-586

46. Bush DA, McAllister CJ, Loredo LN, Johnson WD, Slater JM, Slater JD (2002) Fractionated proton beam radiotherapy for acoustic neuroma. Neurosurgery. 50(2):270-273 discussion 3-5

47. Chung LK, Nguyen TP, Sheppard JP, Lagman C, Tenn S, Lee P, Kaprealian T, Chin R, Gopen Q, Yang I (2018) A systematic review of radiosurgery versus surgery for neurofibromatosis type 2 vestibular schwannomas. World Neurosurg 109:47-58

48. Aoyama H, Onodera S, Takeichi N, Onimaru R, Terasaka S, Sawamura Y et al (2013) Symptomatic outcomes in relation to tumor expansion after fractionated stereotactic radiation therapy for vestibular schwannomas: single-institutional long-term experience. Int J Radiat Oncol Biol Phys. 85(2):329-334

49. Chihara Y, Ito K, Sugasawa K, Shin M (2007) Neurological complications after acoustic neurinoma radiosurgery: revised risk factors based on long-term follow-up. Acta Otolaryngol 127:65-70

50. Ito K, Shin M, Matsuzaki M, Sugasawa K, Sasaki T (2000) Risk factors for neurological complications after acoustic neurinoma radiosurgery: refinement from further experiences. Int J Radiat Oncol Biol Phys. 48(1):75-80

51. Yang I, Sughrue ME, Han SJ, Fang SN, Aranda D, Cheung SW et al (2009) Facial nerve preservation after vestibular schwannoma gamma knife radiosurgery. J Neurooncol 93(1):41

Publisher's note Springer Nature remains neutral with regard to jurisdictional claims in published maps and institutional affiliations. 